\title{
Analisis Kompetensi Inti 3 (KI-3) Kurikulum 2013 pada Kelas XI SMA Berdasarkan Taksonomi Bloom Revisi
}

\section{Analysis of Core Competency 3 of Curriculum 2013 for 11th Grade of Senior High School Based on Taxonomy Bloom (Revised Version)}

\author{
Khoirunnisah $^{1}$ and E Yusmaita ${ }^{1^{*}}$ \\ ${ }^{1}$ Pendidikan Kimia, Universitas Negeri Padang, Jl. Prof. Dr. Hamka, Air Tawar Barat, \\ Padang Utara, Sumatera Barat, Indonesia 25171 \\ *ekayusmaita@fmipa.unp.ac.id
}

ARTICLE INFO

Received 12 October 2019

Revised 20 October 2019

Published 21 October 2019

\begin{abstract}
The 2013 curriculum is the latest curriculum used as a guideline for organizing learning activities to achieve educational goals. The fundamental change in the 2013 curriculum is that core competencies must be arranged in a balanced manner covering attitudes (spiritual and social), knowledge and skills. The purpose of this study is to describe the formula of KI-3 outlined based on the revised Bloom taxonomy. Taxonomy is used as one of the references in the preparation of $\mathrm{KI}-3$ starting from the cognitive dimension and the lowest dimension of knowledge to the highest or complex level. This type of research is descriptive with a qualitative approach. Data collection techniques used by library research. The data source used is Permendikbud No. 37 of 2018. The formula KI-3 was analyzed based on knowledge activities, types of knowledge, and scientific attitudes. The results of the elaboration of KI-3 class XI SMA obtained 48 components of KI-3. The KI-3 component that has been described is used as a reference for the dimensions of cognitive processes and the dimensions of knowledge that must be achieved by students.
\end{abstract}

\section{KEYWORDS}

Analysis, 2013 Curriculum, Core Competency, bloom revised taxonomy

\begin{abstract}
ABSTRAK
Kurikulum 2013 merupakan kurikulum terbaru yang dijadikan sebagai pedoman penyelenggaraan kegiatan pembelajaran untuk mencapai tujuan pendidikan. Perubahan mendasar pada kurikulum 2013 adalah kompetensi harus disusun seimbang mencakup sikap (spritual dan sosial), pengetahuan, dan keterampilan. Tujuan dari penelitian ini adalah untuk mendeskripsikan rumusan KI-3 yang diuraikan berdasarkan taksonomi Bloom revisi. Taksonomi dijadikan sebagai salah satu acuan dalam penyusunan KI-3 yang dimulai dari dimensi kognitif dan dimensi pengetahuan level yang paling rendah sampai tingkatan yang paling tinggi atau kompleks. Jenis penelitian yang digunakan adalah deskriptif dengan pendekatan kualitatif. Teknik pengumpulan data yang digunakan adalah studi kepustakaan. Sumber data yang digunakan adalah Permendikbud No. 37 Tahun 2018. Rumusan KI-3 dianalisis berdasarkan aktivitas pengetahuan, jenis pengetahuan, dan sikap ilmiah. Hasil jabaran dari KI-3 kelas XI SMA didapatkan sebanyak 48 komponen KI-3. Komponen KI-3 yang telah dijabarkan digunakan sebagai acuan dimensi proses kognitif dan dimensi pengetahuan yang harus dicapai oleh peserta didik.
\end{abstract}

KATA KUNCI

Analisis, Kurikulum 2013, Kompetensi Inti 3, Taksonomi Bloom revisi 


\section{PENDAHULUAN}

Kurikulum adalah seperangkat rencana dan pengaturan mengenai tujuan, isi dan bahan pelajaran serta cara yang digunakan sebagai pedoman penyelenggaraan kegiatan pembelajaran untuk mencapai tujuan-tujuan pendidikan ${ }^{[1]}$. Dalam suatu sistem pendidikan, kurikulum selalu mengalami perubahan dan perkembangan sesuai dengan perkembangan masyarakat dan tuntutan zaman. Kurikulum yang diterapkan di Indonesia saat ini adalah kurikulum 2013.

Kurikulum 2013 merupakan wujud dari pengembangan dan penyempurnaan Kurikulum 2006 (KTSP) yang menitikberatkan pada penyempurnaan pola pikir, penguatan proses pembelajaran, penguatan tata kelola kurikulum, penyesuaian beban belajar, dan pendalaman dan perluasan materi agar dapat menjamin kesesuaian antara apa yang diinginkan dengan apa yang dihasilkan. Perubahan mendasar pada kurikulum 2013 adalah kompetensi inti harus disusun seimbang mencakup sikap (spritual dan sosial), pengetahuan dan keterampilan ${ }^{[2]}$. Oleh sebab itu kurikulum 2013 dirancang dengan karakteristik mengembangkan keseimbangan antara sikap spiritual dan sosial, rasa ingin tahu, kreativitas, kerja sama, kemampuan intelektual dan psikomotorik dimana peserta didik menerapkan apa yang dipelajari di sekolah ke masyarakat dan memanfaatkan masyarakat sebagai sumber belajar untuk mengembangkan sikap, pengetahuan dan keterampilan ${ }^{[3]}$. Keberhasilan kurikulum 2013 tergantung pada perumusan dan pelaksanaannya. Salah satu kerangka dasar yang mengkategorikan tujuan-tujuan pendidikan dan penyusunan kurikulum adalah taksonomi Bloom yang disusun berdasarkan dimensi proses kognitif dan dimensi pengetahuan.

Taksonomi bertujuan untuk mengelompokkan tujuan pembelajaran, pengajaran dan sasaran belajar yang digolongkan dalam tiga ranah (domain), yaitu (1) ranah kognitif berkaitan dengan kemampuan berpikir, (2) ranah afektif berkaitan dengan sikap dan perilaku , (3) ranah psikomotorik berkaitan dengan penggunaan otot kerangka atau keterampilan motorik ${ }^{[4]}$. Ketiga ranah dimasukkan kedalam kurikulum 2013 yang dirumuskan pada empat kompetensi inti, yaitu KI 1 (sikap spritual), KI 2 (sikap sosial), KI 3 (pengetahuan) dan KI 4 (keterampilan).

Taksonomi Bloom revisi terdapat enam kategori dimensi proses kognitif yang dimulai dari hierarki yang sederhana sampai yang paling kompleks. Tujuan pada jenjang yang lebih kompleks tidak akan tercapai apabila jenjang yang dibawahnya belum tercapai. Dimulai dari level paling rendah mengingat, memahami, menerapkan, menganalisis, mengevaluasi, dan mencipta. Enam tingkatan tujuan belajar aspek kognitif dikenal dengan singkatan C1 sampai C6. Pada taksonomi Bloom revisi dimensi kognitif dan dimensi pengetahuan dipisahkan, dikarenakan dimensi kognitif merupakan kata kerja sedangkan dimensi pengetahuan merupakan kata benda. Pemisahan ini didasarkan agar guru dapat mengukur jenis pengetahuan apa yang belum tercapai ${ }^{[5]}$. Dimensi pengetahuan dikelompokkan menjadi empat macam pengetahuan dari yang sifatnya konkret hingga abstrak, yaitu pengetahuan faktual, konseptual, prosedural dan metakognitif ${ }^{[6]}$. Pencapaian dimensi kognitif pada KI-3 yang dilihat dari penggunaan Kata Kerja Operasional (KKO) dan dimensi pengetahuan berbeda disetiap jenjang pendidikan. Tingkat kompetensi yang berbeda menuntut pembelajaran dan penilaian dengan penekanan dan fokus yang berbeda pula. Semakin tinggi tingkat kompetensi maka semakin kompleks pula intensitas proses pembelajaran dan pengalaman belajar serta penilaian ${ }^{[7]}$.

Dengan demikian, perlu dilakukan analisis terhadap KI 3 untuk melihat tingkatan dimensi proses kognitif dan dimensi pengetahuan yang harus dicapai oleh peserta didik berdasarkan taksonomi Bloom revisi. Dimana analisis ini adalah kegiatan menguraikan material menjadi bagianbagian penyusunnya dan menentukan bagaimana bagian-bagian tersebut saling terkait satu sama lain dengan keseluruhan struktur dan tujuan ${ }^{[8]}$.

\section{METODE}

Jenis penelitian yang digunakan adalah penelitian deskriptif dengan pendekatan kualitatif. Teknik pengumpulan data menggunakan studi kepustakaan (Library Research). Sumber data penelitian ini adalah Permendikbud No. 37 Tahun 2018 dan taksonomi Bloom revisi. Data yang dijelaskan dalam penelitian ini adalah hasil analisis kompetensi inti 3 berdasarkan taksonomi Bloom revisi yang dibatasi pada kurikulum 2013 revisi 2018 kelas XI SMA.

\section{HASIL DAN DISKUSI}

\subsection{Hasil Penelitian}

Berdasarkan taksonomi Bloom revisi analisis adalah kegiatan menguraikan, mengorganisir dan menemukan pesan tersirat. KI-3 pada kelas XI SMA dirumuskan dengan kalimat "memahami, menerapkan, dan menganalisis pengetahuan faktual, konseptual, prosedural dan metakognitif tentang ilmu pengetahuan alam, teknologi, seni, budaya, dan humaniora dengan wawasan kemanusiaan, kebangsaan, kenegaraan, dan peradaban terkait penyebab fenomena dan kejadian, serta menerapkan pengetahuan prosedural pada bidang kajian yang spesifi sesuai dengan bakat dan minatnya untuk memecahkan masalah" ${ }^{[9]}$. Rumusan KI-3 disusun dalam satu rumusan kalimat yang umum memuat aktivitas pengetahuan, jenis pengetahuan, sikap ilmiah dan objek dalam bidang kajian yang akan dipelajari oleh peserta didik kelas XI SMA Hasil penguraian dan penjabaran dari rumusan KI-3 dapat dilihat pada Tabel 1 . 
Tabel 1. Analisis Kompetensi Inti 3

Memahami, menerapkan, dan menganalisis pengetahuan faktual, konseptual, prosedural dan metakognitif tentang ilmu pengetahuan alam, teknologi, seni, budaya, dan humaniora dengan wawasan kemanusiaan, kebangsaan, kenegaraan, dan peradaban terkait penyebab fenomena dan kejadian, serta menerapkan pengetahuan prosedural pada bidang kajian yang spesifi sesuai dengan bakat dan minatnya untuk memecahkan masalah.

\begin{tabular}{|c|c|c|c|c|}
\hline \multicolumn{2}{|c|}{$\begin{array}{l}\text { Dimensi Proses } \\
\text { Kognitif }\end{array}$} & Dimensi Pengetahuan & Sikap Ilmiah & $\begin{array}{c}\text { Komponen } \\
\text { KI-3 }\end{array}$ \\
\hline \multirow{7}{*}{$\begin{array}{c}\text { Mema- } \\
\text { hami (C2) }\end{array}$} & Menafsirkan & \multirow{12}{*}{$\begin{array}{l}\text { - Faktual } \\
\text { - } \quad \text { Pengetahuan tentang terminologi } \\
\text { - } \quad \text { Pengetahuan tentang bagian detail } \\
\text { dan unsur-unsur } \\
\text { - Konseptual } \\
\text { - } \quad \text { Pengetahuan tentang klasifikasi } \\
\text { dan kategori } \\
\text { - } \quad \text { Pengetahuan tentang prinsip dan } \\
\text { generalisasi } \\
\text { - Pengetahuan tentang teori, model, } \\
\text { dan struktur } \\
\text { Prosedural } \\
\text { - Pengetahuan tentang keterampi- } \\
\text { lan khusus dengan suatu bidang } \\
\text { tertentu dan pengetahuan tentang } \\
\text { algoritme } \\
\text { - Pengetahuan tentang teknik dan } \\
\text { metode yang berhubungan dengan } \\
\text { suatu bidang tertentu } \\
\text { - Pengetahuan tentang kriteria } \\
\text { untuk menentukan kapan suatu } \\
\text { prosedur tepat untuk digunakan } \\
\text { Metakognitif } \\
\text { - Pengetahuan tentang strategi } \\
\text { - Pengetahuan tentang konteks dan } \\
\text { kondisi yang sesuai } \\
\text { - Pengetahuan tentang diri sendiri }\end{array}$} & \multirow{12}{*}{$\begin{array}{l}\text { Rasa ingin } \\
\text { tahu }\end{array}$} & 4 komponen KI \\
\hline & $\begin{array}{l}\text { Memberi } \\
\text { contoh }\end{array}$ & & & 4 komponen $\mathrm{KI}$ \\
\hline & $\begin{array}{l}\text { Mengklasi- } \\
\text { fikasikan }\end{array}$ & & & 4 komponen $\mathrm{KI}$ \\
\hline & Meringkas & & & 4 komponen $\mathrm{KI}$ \\
\hline & $\begin{array}{l}\text { Menarik } \\
\text { inferensi }\end{array}$ & & & 4 komponen $\mathrm{KI}$ \\
\hline & $\begin{array}{l}\text { Memband- } \\
\text { ingkan }\end{array}$ & & & 4 komponen $\mathrm{KI}$ \\
\hline & $\begin{array}{l}\text { Menjelas- } \\
\text { kan }\end{array}$ & & & 4 komponen $\mathrm{KI}$ \\
\hline \multirow{2}{*}{$\begin{array}{l}\text { Menjalan- } \\
\text { kan (C3) }\end{array}$} & $\begin{array}{l}\text { Menjalan- } \\
\text { kan }\end{array}$ & & & 4 komponen $\mathrm{KI}$ \\
\hline & $\begin{array}{l}\text { Mengimpe- } \\
\text { lementasi- } \\
\text { kan }\end{array}$ & & & 4 komponen $\mathrm{KI}$ \\
\hline \multirow[b]{3}{*}{$\begin{array}{l}\text { Mengana- } \\
\text { lisis (C4) }\end{array}$} & $\begin{array}{l}\text { Mengurai- } \\
\text { kan }\end{array}$ & & & 4 komponen $\mathrm{KI}$ \\
\hline & $\begin{array}{l}\text { Mengorgan- } \\
\text { isir } \\
\end{array}$ & & & 4 komponen $\mathrm{KI}$ \\
\hline & $\begin{array}{l}\text { Menemu- } \\
\text { kan pesan } \\
\text { tersirat }\end{array}$ & & & 4 komponen $\mathrm{KI}$ \\
\hline
\end{tabular}

Contoh Komponen KI:

C2 : Menafsirkan

Menafsirkan pengetahuan faktual berdasarkan rasa ingin tahunya tentang ilmu pengetahuan, teknologi, seni, budaya, dan humaniora dengan wawasan kemanusiaan, kebangsaan, kenegaraan, dan peradaban terkait penyebab fenomena dan kejadian, serta menerapkan pengetahuan prosedural pada bidang kajian yang spesifik sesuai dengan bakat dan minatnya untuk memecahkan masalah.

C3: Menjalankan

Menafsirkan pengetahuan faktual berdasarkan rasa ingin tahunya tentang ilmu pengetahuan, teknologi, seni, budaya, dan humaniora dengan wawasan kemanusiaan, kebangsaan, kenegaraan, dan peradaban terkait penyebab fenomena dan kejadian, serta menerapkan pengetahuan prosedural pada bidang kajian yang spesifik sesuai dengan bakat dan minatnya untuk memecahkan masalah.

\section{C4: Menguraikan}

Menafsirkan pengetahuan faktual berdasarkan rasa ingin tahunya tentang ilmu pengetahuan, teknologi, seni, budaya, dan humaniora dengan wawasan kemanusiaan, kebangsaan, kenegaraan, dan peradaban terkait penyebab fenomena dan kejadian, serta menerapkan pengetahuan prosedural pada bidang kajian yang spesifik sesuai dengan bakat dan minatnya untuk memecahkan masalah.

KI-3 yang dirumuskan dalam 1 kalimat yang panjang dan memiliki arti yang sangat umum. Rumusan KI-3 tersusun dari 3 kata kerja yang menunjukkan aktivitas pengetahuan, 4 jenis pengetahuan, sikap ilmiah, dan 5 bidang keilmuan. Oleh sebab itu, maka rumusan KI-3 perlu dilakukan penguraian dan penyusunan kembali kalimat KI agar rumusan KI-3 tersebut lebih sederhana dan mudah dipahami.

Penguraian KI-3 didasarkan pada susunan dari rumusan kalimat KI-3 tersebut, yaitu dengan mengelompokkan aktivitas pengetahuan yang 
berupa kata kerja kedalam dimensi proses kognitif. Pada setiap kata kerja pada proses kognitif diuraikan lagi berdasarkan sub indikator proses kognitif.

\subsection{Pembahasan}

Analisis kompetensi inti 3 dilakukan dengan menguraikan, mengorganisir dan menemukan pesan tersirat dari dimensi proses kognitif dan dimensi pengetahuan yang mengacu pada taksonomi Bloom revisi. Pada penelitian ini rumusan KI yang dianalisis yaitu "memahami, menerapkan, dan menganalisis pengetahuan faktual, konseptual, prosedural, dan metakognitif berdasarkan rasa ingin tahunya tentang ilmu pengetahuan, teknologi, seni, budaya, dan humaniora dengan wawasan kemanusiaan, kebangsaan, kenegaraan, dan peradaban terkait penyebab fenomena dan kejadian, serta menerapkan pengetahuan prosedural pada bidang kajian yang spesifik sesuai dengan bakat dan minatnya untuk memecahkan masalah".

Berdasarkan hasil analisis rumusan KI-3 kelas XI kimia SMA tidak menggunakan semua tingkat dalam dimensi proses kognitif, namun hanya menuntut dimensi proses kognitifnya mulai dari C2 sampai C4, yaitu memahami (C2), menerapkan (C3) dan menganalisis (C4). Dimensi kognitif yang harus dicapai sesuai dengan rumusan KI-3 pada kelas XI SMA dengan level terendah "memahami' dan level paling tinggi "menganalisis". Pada taksonomi Bloom revisi masing-masing dimensi kognitif dikelompokkan menjadi masingmasing kategori. Pada dimensi proses kognitif "memahami" ada tujuh macam proses kognitif, yaitu (1) menafsirkan, (2) memberikan contoh, (3) mengklasifikasikan, (4) meringkas, (5) menarik inferensi, (6) membandingkan, dan (7) menjalaskan. Dimensi proses kognitif "menerapkan" ada dua macam proses kognitif, yaitu: (1) menjalankan dan (2) mengimplementasikan. Dan dimensi proses kognitif "menganalisis" ada tiga macam, yaitu: (1) menguraikan, (2) mengorganisir dan (3) menemukan pesat tersirat.

Dimensi pengetahuan pada rumusan KI-3 hanya menuntut 4 jenis pengetahuan yaitu pengetahuan faktual, konseptual, prosedural dan metakognitif. Dimensi pengetahuan dikategorikan berdasarkan tingkatan dari yang paling konkret sampai yang bersifat abstrak. Pengetahuan faktual terbagi menjadi 2, yaitu: (1) pengetahuan tentang terminologi, (2) pengetahuan tentang bagian detail dan unsur-unsur. Pengetahuan konseptual meliputi skema, model dan teori yang berisi informasi yang saling berkaitan dan sistematis. Pengetahuan ini terbagi menjadi 3, yaitu (1) pengetahuan tentang klasifikasi dan teori, (2) pengetahuan tentang generalisasi dan prinsip, (3) pengetahuan tentang teori, model dan struktur. Pengetahuan prosedural terbagi menjadi 3 macam, yaitu: (1) pengetahuan tentang keterampilan khsus yang berhubungan dengan suatu bidang tertentu dan pengetahuan tentang algoritme, (2) pengetahuan tentang teknik dan metode yang berhubungan dengan suatu bidang tertentu dan pengetahuan tentang kriteria untuk menentukan penggunaan prosedur. Pengetahuan metakognitif terbagi menjadi 3, yaitu: (1) Pengetahuan strategi, (2) pengetahuan tugas kognitif, (3) pengetahuan tentang diri sendiri ${ }^{[6]}$. Hubungan antara dimensi kognitif dan dimensi pengetahuan dapat dilihat pada Tabel 2 .

Tabel 2. Hubungan Dimensi Kognitif dan Dimensi Pengetahuan $^{[8]}$

\begin{tabular}{c|c|c} 
No. & $\begin{array}{c}\text { Perkembangan } \\
\text { Berfikir Taksonomi } \\
\text { Bloom Revised An- } \\
\text { derson (Cognitive } \\
\text { Process Dimen- } \\
\text { sion) }\end{array}$ & $\begin{array}{c}\text { Bentuk Pengeta- } \\
\text { huan (Knowledge } \\
\text { Dimension) }\end{array}$ \\
\hline 1 & Mengingat (C1) & Pengetahuan Faktual \\
\hline 2 & $\begin{array}{c}\text { Memahami/ } \\
\text { Menginterprestasi } \\
\text { Prinsip (C2) }\end{array}$ & $\begin{array}{c}\text { Pengetahuan } \\
\text { Konseptual }\end{array}$ \\
\hline 3 & $\begin{array}{c}\text { Menerapkan (C3) } \\
\text { Pengetahuan } \\
\text { Prosedural }\end{array}$ \\
\hline 5 & Menganalisis (C4) & $\begin{array}{c}\text { Pengetahuan } \\
\text { Metakognitif }\end{array}$ \\
\hline 6 & Mengevaluasi (C5) & Mencipta (C6) \\
\multicolumn{2}{|c|}{ Pada setiap kata kerja pada proses kognitif }
\end{tabular}
diuraikan lagi berdasarkan sub indikator proses kognitif. Misalnya pada dimensi proses kognitif memahami memiliki 7 sub indikator. Jenis pengetahuan pada KI-3 dikelompokkan dalam dimensi pengetahuan. Selain itu, kompetensi inti 3 menuntut peserta didik agar memiliki sikap ilmiah "rasa ingin tahu" yang merupakan bagian dari kompetensi dari muatan kimia untuk kelompok peminatan matematika dan ilmu-ilmu alam pada SMA/MA/SMALB/PAKET C. Hal ini sesuai dengan tujuan kurikulum 2013 yang menganggap pentingnya penanaman sikap ilmiah pada peserta didik yang dapat memberikan pengalaman belajar bermakna dengan cara mengembangkan berbagai sikap $^{[10]}$. Sehingga disimpulkan bahwa dalam KI-3 menuntut peserta didik untuk menumbuhkan rasa ingin tahunya terhadap apa yang akan dipelajari di sekolah.

Penyusunan kembali kalimat KI-3 dilakukan dengan menggabungkan hasil penguraian menjadi kalimat KI yang lebih sederhana, namun tidak mengurangi dan merubah makna dan susunan dari kalimat awal KI-3. Penyusunan kembali kalimat KI-3 akan menghasilkan 1 kalimat komponen KI-3 yang terdiri dari 1 sub indikator dimensi proses kognitif, 1 jenis dimensi pengetahuan, dan sikap ilmiah. Maka rumusan KI setelah dilakukan penguraian dan penjabaran yang dicontohkan pada salah satu dimensi proses kognitif adalah sebagai berikut:

"Menafsirkan pengetahuanfaktual berdasarkan rasa ingin tahunya tentang ilmu pengetahuan, 
teknologi, seni, budaya, dan humaniora dengan wawasan kemanusiaan, kebangsaan, kenegaraan, dan peradaban terkait penyebab fenomena dan kejadian, serta menerapkan pengetahuan prosedural pada bidang kajian yang spesifik sesuai dengan bakat dan minatnya untuk memecahkan masalah (C2)".

"Menafsirkan pengetahuan konseptual berdasarkan rasa ingin tahunya tentang ilmu pengetahuan, teknologi, seni, budaya, dan humaniora dengan wawasan kemanusiaan, kebangsaan, kenegaraan, dan peradaban terkait penyebab fenomena dan kejadian, serta menerapkan pengetahuan prosedural pada bidang kajian yang spesifik sesuai dengan bakat dan minatnya untuk memecahkan masalah (C2)".

"Menafsirkan pengetahuan prosedural berdasarkan rasa ingin tahunya tentang ilmu pengetahuan, teknologi, seni, budaya, dan humaniora dengan wawasan kemanusiaan, kebangsaan, kenegaraan, dan peradaban terkait penyebab fenomena dan kejadian, serta menerapkan pengetahuan prosedural pada bidang kajian yang spesifik sesuai dengan bakat dan minatnya untuk memecahkan masalah (C2)".

"Menafsirkan pengetahuan metakognitif berdasarkan rasa ingin tahunya tentang ilmu pengetahuan, teknologi, seni, budaya, dan humaniora dengan wawasan kemanusiaan, kebangsaan, kenegaraan, dan peradaban terkait penyebab fenomena dan kejadian, serta menerapkan pengetahuan prosedural pada bidang kajian yang spesifik sesuai dengan bakat dan minatnya untuk memecahkan masalah (C2)".

Kalimat pada bagian rumusan KI-3 "ilmu pengetahuan, teknologi, seni, budaya, dan humaniora dengan wawasan kemanusiaan, kebangsaan, kenegaraan, dan peradaban terkait penyebab fenomena dan kejadian" tidak diuraikan lagi karena kalimat tersebut sebagai kalimat pelengkap pada rumusan KI-3. Rumusan KI-3 dapat disederhanakan dapat dilihat pada contoh dibawah ini:

"Menafsirkanpengetahuanfaktual berdasarkan rasa ingin tahunya tentang ilmu pengetahuan terkait penyebab fenomena dan kejadian, serta menerapkan pengetahuan prosedural pada bidang kajian yang spesifik sesuai dengan bakat dan minatnya untuk memecahkan masalah (C2)."

"Menafsirkan pengetahuan konseptual berdasarkan rasa ingin tahunya tentang ilmu pengetahuan terkait penyebab fenomena dan kejadian, serta menerapkan pengetahuan prosedural pada bidang kajian yang spesifik sesuai dengan bakat dan minatnya untuk memecahkan masalah (C2)."

"Menafsirkan pengetahuan prosedural berdasarkan rasa ingin tahunya tentang ilmu pengetahuan terkait penyebab fenomena dan kejadian, serta menerapkan pengetahuan prosedural pada bidang kajian yang spesifik sesuai dengan bakat dan minatnya untuk memecahkan masalah (C2).”
"Menafsirkan pengetahuan metakognitif berdasarkan rasa ingin tahunya tentang ilmu pengetahuan terkait penyebab fenomena dan kejadian, serta menerapkan pengetahuan prosedural pada bidang kajian yang spesifik sesuai dengan bakat dan minatnya untuk memecahkan masalah (C2)."

Jadi setelah dilakukan penguraian dan penjabaran rumusan KI-3 akan didapatkan 4 komponen KI untuk masing-masing kategori dimensi proses kognitif berdasarkan dimensi pengetahuan. Berdasarkan penyusunan kembali kalimat KI-3, maka dihasilkan 48 kalimat komponen KI-3. Komponen KI-3 yang telah dijabarkan digunakan sebagai acuan dimensi proses kognitif dan dimensi pengetahuan yang harus dikuasai peserta didik tidak boleh melebihi tuntutan dari KI yang dirumuskan.

\section{SIMPULAN}

Hasil penelitian rumusan KI-3 mengandung dimensi kognitif dan dimensi pengetahuan berdasarkan taksonomi Bloom revisi. Kalimat KI-3 memuat aktivitas keterampilan, jenis pengetahuan, sikap ilmiah dan objek dalam bidang kajian yang dijabarkan menghasilkan 4 komponen KI masingmasing kateori dan keseluruhan KI yang dihasilkan adalah 48 komponen KI-3. Komponen KI-3 yang telah dijabarkan digunakan sebagai acuan dimensi proses kognitif dan dimensi pengetahuan yang harus dikuasai peserta didik tidak boleh melebihi tuntutan dari KI yang dirumuskan.

\section{REFERENSI}

1. Undang-Undang No 20 Tahun 2003 Tentang Sistem Pendidikan Nasional.

2. Machali, I. 2014. "Dimensi Kecerdasan Majemuk dalam Kurikulum 2013”. Insania. 19(1). Hlm. 21-45.

3. Peraturan Menteri Pendidikan Dan Kebudayaan Republik Indonesia Nomor 69 Tahun 2013 Tentang Kerangka Dasar dan Struktur Kurikulum Sekolah Menegah Atas/ Madrasah Aliyah

4. Ella, Yulaelawati. 2004. Kurikulum dan Pembelajaran. Jakarta: Pakar Raya.

5. Widodo, A. 2005. "Taksonomi Tujuan Pembelajaran”. Didaktis. 4(2). Hlm. 61-69.

6. Widodo, A. 2006. "Taksonomi Bloom dan Pengembangan Butir Soal”. Buletin Puspendi. 3(2). Hlm. 18-29.

7. Peraturan Menteri Pendidikan dan Kebudayaan Republik Indonesia No. 21 Tahun 2016 Tentang Standar Isi Pendidikan Dasar dan Menengah.

8. Anderson, L.W., dan Krathwohl, D. R. 2001. A Taxonomy for Learning, Teaching, and Assesing: A revision of Bloom's Taxonomy of Educational Objectives. New york: Addison Wesley Longman, Inc.

9. Peraturan Menteri Pendidikan dan Kebudayaan Republik Indonesia No. 37 Tahun 2018 Tentang Kompetensi Inti dan Kompetensi Dasar 
Edukimia $\cdot 2019 \cdot$ Vol. 1, No. 3

Pendidikan Dasar dan Menegah.

10. Nugraha, A.J., Suyitno, $\mathrm{H}$ \& Susilaningsih,

E. 2017. Analisis Kemampuan Berpikir Kritis

Ditinjau dari Keterampilan Proses Sains dan

Motivasi Belajar melalui Model PBL. Journal of

Primary Education (JPE). 6 (1). Hlm. 35-43 